\title{
Getting the Measure of Academia: Universities and the Politics of Accountability
}

\author{
Don Brenneis, Cris Shore and Susan Wright
}

\begin{abstract}
Audit culture and the politics of accountability are transforming not just universities and their role in society, but the very notions of society, academics and students. The modern 'university of excellence' applies a totalising and coercive commensurability to virtually every aspect of university life, from research output and teaching quality to parking space. But more than this, the politics of accountability enmesh universities in conflicts over neoliberal transformations which are taking a wide variety of forms in different parts of Europe, North and South America, and Australasia.
\end{abstract}

'Not everything that counts can be counted, and not everything that can be counted counts.' -Albert Einstein, 1879-1955

\section{The Neoliberalisation of Academia: Universities, Management and Accountability}

In an age when regimes of bureaucratic auditing and competitive star-ratings have become ever-more pervasive and intrusive features of professional life in both the public and private sectors, Einstein's aphorism (quoted above) provides a salutary reminder that not everything that is cherished or valued in society can be subjected to the norms of instrumental calculation or financial accountancy. That such a seemingly self-evident point needs to be emphasised is itself a revealing indicator of just how far modern societies seem to have succumbed to the hegemony of what some anthropologists have called the disciplinary norms of 'audit culture' (Shore and Wright 1999; Strathern 2000). Nowhere is this phenomenon more evident than in higher education, a sector of the economy that has undergone a massive transformation as a result of various neo- liberal policies and programmes that have driven the reform agenda since the 1980s. It was against this background of what Tickel and Peck (2003) have termed 'neoliberalisation' that our panel on 'Audit Culture and the Politics of Accountability' (on which this special issue of Anthropology In Action is based) met in November 2003 at the AAA conference in Chicago. Our aim was to engage in a free and frank exchange of anthropological reflections on the changing role of the university as an institution. The issues that framed this discussion were how best to conceptualise and understand those changes, and beyond this, how changes in the idea of the university reflect and relate to wider processes of economics, politics and governance in modern societies. In short, how are we-as academics, educationalists, public sector employees, professionals and students-positioned within those systems of power? How are changes in the management and organisation of tertiary-sector education - the so-called 'quality revolu- 
tion'-shaping the ways universities relate to society and the ways, as academics, we relate to our profession, to our colleagues and students, and to ourselves?

This debate is both important and timely for three reasons. First, because one of the defining qualities of anthropology as a discipline is its epistemological reflexivity and its capacity to think critically about the conditions of its own existence and, beyond this, about the way knowledge is produced. As the university is the primary institution for the cultural reproduction of anthropology as a discipline, it is important to understand what is happening to the conditions of work and thought in which we operate-and the way these influence knowledge production and what 'counts' as valid or 'robust knowledge' (Strathern 2003). Second, this debate is important because those conditions of existence have undergone radical reforms since the late 1980s, changes so profound that some scholars argue that it is no longer clear what is the role of the modern university today. The traditional liberal/ Enlightenment idea of the university as a community of teachers and students dedicated to the rational and disinterested pursuit of 'higher learning' as an end in itself is fast being replaced by the idea of the university as a transnational corporate enterprise whose function is to provide a skilled workforce and relevant and usable research for the new Global Knowledge Economy. The British Government's recent White Paper on The Future of Higher Education sums this up succinctly:

We see a higher education sector which meets the needs of the economy in terms of trained people, research and technology transfer. At the same time it needs to enable all suitably qualified individuals to develop their potential both intellectually and personally, and to provide the necessary storehouse of expertise in science and technology, and the arts and humanities which defines our civilization and culture. (Cited in Collini $2003: 3$ )
As Collini notes, that long and convoluted sentence contains all the different aims that government now expects universities to fulfil (which perhaps explains why universities in Britain are so demoralised). The very idea of the university has changed.

Third, the metamorphosis of universities into transnational corporate enterprises has entailed the creation of a raft of new bureaucratic mechanisms and procedures designed to render universities more accountable, manageable, efficient and 'visible' to those agencies and inspectors concerned with the measurement of performance. As universities have increasingly defined their constituencies, students and funding sources internationally, the apparent need for comparability of courses and degrees, as well as of expectations and standards, has helped drive this push towards accountability. Since the 1990s, we have witnessed a spectacular growth of new managerial models and methods aimed at 'enhancing performance' and assuring the quality of teaching and learning. This is reflected most clearly in the wholesale import into higher education of the language and concepts of commerce and private-sector management, including terms such as 'mission statements', 'output performance indicators', and annual staff reviews - and the reclassification of students and their parents as 'customers', 'stakeholders' or 'consumers' of educational products and services. This shift in the discourse of higher education towards an emphasis on the preeminent role of markets and New Public Management systems also provides fertile ground for a critical and reflexive anthropology. On closer analysis it appears that the processes of neoliberalism, structural adjustment and globalisation that anthropologists have so often studied in Third World and developing countries are also evident in the Western universities in which many of us work. 


\section{The University of 'Excellence'}

To echo Bill Readings' (1996: 13) in his celebrated book, The University in Ruins, the 'grand narrative' that traditionally defined the function of the university has shifted from the Kantian concept of 'reason' and the Humboldtian idea of 'culture' to the modern techno-bureaucratic idea of 'excellence'. Unlike its predecessors, the 'university of excellence' is less concerned with issues of scholarship or disciplinary knowledge than with 'best practice', 'quality assurance', 'output and productivity' and 'value for money'. What is taught or researched matters far less than 'the fact that it be excellently taught or researched' (Readings 1996: 13, our emphasis). Readings makes a further and particularly salient observation about the nature of this semantic and conceptual shift. It is anachronistic to think of 'excellence' as an ideology, he says. What makes it so effective as a political instrument is that excellence has no content: like the cash-nexus, it is neither true nor false. 'Excellence' presents itself as emphatically nonideological-which is precisely why it is so hard to contest or challenge-after all, what reasonable person could possibly be opposed to raising standards or enhancing quality? In this respect, 'excellence' functions as a very effective type of political technology; one that successfully removes what is in essence a political problem and recasts it in the neutral language of science and technology so that it is elevated onto a plain beyond political intervention and cannot be effectively challenged or debated. Like the pursuit of virtue or happiness, everyone must naturally be in favour of promoting excellence.

But excellence also provides a yardstick for drawing together under one unifying and totalising measure virtually every aspect of university life: hence, indices of excellence are applied equally to the quali- ty of academic research and teaching, and to the delivery of canteen services and car parking facilities. This is but one small example of what we have termed 'coercive commensurability' or the tyranny of numbers: the compulsion to reduce complex social activities to simple numerical scores or ratings so that these, in turn, can be monitored, assessed, displayed and competitively ranked. The rise of the league table in the UK, a system for comparing performance and measures of 'excellence' in schools, hospitals, the police, ambulance services and local government, is perhaps the most visible manifestation of the way this coercive commensurability works. Competitive league tables-such as those used to compare university research ratings and teaching quality-then provide the instrument for allocating resources: the winners are to be lauded, while the losers must be vilified and punished.

The university of excellence has not simply superseded or replaced the universities of reason and culture: a further feature of this transformation is that it is partial and incomplete. Instead, these three different models coexist, often in overlapping and contradictory ways. A vivid example of this was the 'New Staff Induction Day' at the University of Auckland attended by Cris Shore in June 2003. Some thirty new staff were gathered in the faded splendour of Old Government House, one of Auckland's oldest colonial-style, wooden buildings. The first presentation by the Pro-Vice Chancellor for Academic Affairs gave an overview of how the university works, its committee structure and a brief history of the institution. He ended by reminding his audience about the New Zealand Government Act that upholds the principle of academic freedom and requires universities to be the 'critical consciousness of society'. The university staff's role was to educate students to be responsible citizens and members of society. This 
speech was followed with another from the Pro-Vice Chancellor for Research who spoke almost entirely about money. Using colourful PowerPoint graphs, he showed just how much external income each faculty had secured, talked at length about the university's various commercial patents (to date, 104 and rising) and how much revenue these brought in to the university. He then went into great detail describing UniServices Limited-a body that commercializes the University's intellectual property estate, forms new businesses, and generates over half the University's total research revenues.

This dualism between the liberal concept of education for citizenship and intellectual growth and the idea that higher education's primary function is to provide a spur for economic growth is also manifest in the way most universities now define themselves. For example, the University of Auckland (2003: 91) describes itself in its draft strategic plan as 'a research-led, international university, recognized for excellence in teaching, learning, research, creative work, and administration' and for its 'commitment to serve its local, national and international communities'. However, its international imperative encompasses two very different visions and agendas. The first is:

The classical idea of a University as a community of scholars whose boundaries are not limited by political constraints, by geographical boundaries, or by preconceived ideas of reality or correctness; an institution that imparts universal knowledge in the classical traditions of the cultures and common human values it reflects; and an institution that educates students as responsible and contributing members of, and as future leaders of, their societies. (University of Auckland 2003 : 91)

This contrasts strikingly with the second, more market-oriented and neoliberal vision:

The modern idea of a University as a leader in innovation and the creation of knowledge and development of intellectual and social capital, contributing to the advancement of the human condition generally and the increase in wealth and living standards in their local society in particular (University of Auckland 2003: 91).

What we see here is a new mix of expectations and metaphors used to portray the purpose of the university as an institution. Today's university is now expected to succeed with the paradoxical goals of fostering, through 'culture', the creation of a sort of managerial elite while training a mass of students to underpin the industrial requirements of a nation operating in a competitive global economy dedicated to wealth creation and the exploitation of patents and other forms of intellectual capital (Smith and Webster 1997: 1).

\section{The University and Social Accountability}

The purpose of universities is also being reshaped by another agenda concerning their accountability to society. As Marilyn Strathern (this issue) notes, many anthropologists welcome the new emphasis on the social relevance of research and the involvement of members of society in the research process. Anthropologists have long debated whether and how these issues can be accommodated within the methodologies and politics of anthropological knowledge creation. Yet Strathern has identified a shift in the discourse about the social responsibility and relevance of research that has serious implications not just for anthropology but for disciplines as a whole. She quotes examples of how the notion of relevance is associated with policy makers, for example, setting the research questions posed by what they consider to be the big problems facing society. They are seeking 'comprehensive' approaches, by which is meant 
research that both is interdisciplinary and involves the public. Only this kind of research is deemed 'accountable' to society. She shows how this framing of research is based on a new way of imagining the relation between university and society, encapsulated in two conceptual figures in the research process.

The first figure is the ILP (independent/imagined lay person). Sometimes ILPs are actual people involved in face-toface interaction with scientists, but more often they are a conception in the mind of the scientist-construed variously as the user of knowledge, the representative of a pressure group, the concerned citizen, the espouser of conservative values or the luddite. Reciprocally, Strathern suggests there is an IDE (imagined disciplinary expert). Strathern's Orwellian future of comprehensive knowledge creation gives little space for disciplines to continue to generate their own research questions. Rather, 'those who know best' identify the social problems and assemble a team who can contribute relevant disciplinary expertise. Disciplines are reduced to a source of expertise with functional utility. In this version of social relevance and accountability, both society and disciplines are conceptually brought into the model of a comprehensive research process. This is an imaginary, dressed in a discourse of social accountability which cannot be ignored or denied. However, as with the incorporation of student voices into processes to make universities accountable (Shore and Wright 2004), the actual political engagement of real people in such research may turn out to be far less empowering than the discourse implies.

There are far less subtle and more overtly confrontational attempts by neoliberal politicians in France to change the direction of academic research and equate public accountability with a neoliberal agenda devoted to rooting out the effects of the
1968 generation. This has become particularly pronounced since the defeat of the Left in the French parliamentary elections of 2002. Abélès (this issue) reports on the pressure being placed on the main statefunded research institution, the CNRS, to support disciplines with traditional, positivistic values. This plays into disciplinary politics and helps scientific subjects dominate the institution. Psychoanalysis, philosophy and anthropology are the targets of a wave of criticism, which equates poststructural social critique with disorder. Even former collaborators with Foucault have turned his politics into a neoliberal regime of instrumental economy and efficiency. This is not just a bid to control the research institute but, considering its influence on the French conceptualisation of society and politics, to reassert as normative the reintegration of the individual in society. In Spain, as DiGiacomo details (this issue), control of the system to audit universities is enmeshed in the political conflict between the Catalan Government's autonomy and the Spanish Government's attempts to regain centralised control.

If these examples demonstrate that, in the name of accountability, neoliberal strategies to reshape the relation of the university to society take very different forms within Europe, Ribeiro introduces a further case from outside Europe. Anthropology in Brazil has a strong tradition of community involvement and progressive politics which perhaps makes it immune to criticisms of irrelevance and lack of accountability. The very continuation of anthropology departments is instead affected by pressures from the World Bank and IMF to downsize the public sector, especially the high quality public university system, and let private capital enter the sector. Anthropology is a graduate subject and only located in the elite public universities. These universities are being eroded 
by state policies to retire established academics and underfund new ones so that they prioritise consultancies and teaching and research become secondary. To Ribeiro, 'quality' and 'accountability' remain positive, progressive terms because, here at least, they provide a basis for professionals to resist the tide of commercialisation. In Brazil new private colleges are being opened at an unprecedented rate-every six hours-and these colleges now have more than half the country's students. In the Brazilian context, quality is one of the last remaining barriers between public and private universities.

Like Brazil, the politics of accountability in Australia also reflect global processes of neoliberalisation, yet here, too, these have a particular national character and inflection. As Jolly (this issue) shows, successive conservative governments have extended and deepened the Labour Government's attempt to create a new and more flexible industrial relations regime. Here, in universities, as in other public bodies, opposition to the collective bargaining power of unions was sanctified by a discourse of individual 'choice'. Whereas in Britain, government intervention into the internal practices of universities has made extensive use of councils and regulatory bodies-often staffed by academics themselves-in Australia, federal governments have imposed their will more directly. They have the power to police the auditing requirements attached to universities' funding from the Ministry of Education. This idea of social or public accountability seems to have little to do with universities' relations 'outwards' to society, or even to imaginary figures standing for society. Instead it makes universities more accountable 'upwards' and increases the power of government to intervene in universities' internal priorities and practices.

\section{Neoliberalism, 'Enterprise' and University Accountability}

What these examples illustrate are not simply the different national histories of the complex relationship between universities, society and the state, but also the different, changing and often contradictory ways in which the idea of the university is being reconfigured by wider processes of economics, politics and governance in modern societies. As we have seen, university reform has been driven not only by notions of relevance and social accountability and the desire to instill within them the values of 'enterprise culture', but also by the desire to subject universities to commercial considerations and new regimes of economy, efficiency and control. The rationale for this is that, as public institutions and recipients of taxpayers' money, universities must be made 'more accountable' to their various 'stakeholders' and to the public. Tlili and Wright (this issue) analyse current UK government policy for universities to be accountable to their principal stakeholders and consumers: students. Their empirical study shows the weakness of the systems that are meant to incorporate students' voices into university decision making. The key question here, however, is who stands in for the public if not the state and its representative? And what model of accountability is most appropriate for a university? As Marilyn Strathern's (2003) paper 'Accountability Across Disciplines' notes, academic disciplines have an in-built accountability of sorts in the way they engage with knowledge. However, under the current regime of audit-driven managerialism, that kind of accountability no longer 'counts', in the sense that Einstein intended. Instead, universities must be held to account through a complicated set of compulsory audits, external assessments, internal inspections and other quality 
assurance mechanisms designed to guarantee standards and, where necessary, enhance performance and productivity.

Most universities have adopted a managerialist form of accountability geared to measuring and enhancing 'productivity'. Regular external and internal audits of research output and teaching quality have thus become the norm. Academics accept these in part because they are couched in the benign and unassailable language of transparency and accountability, which is hard to oppose or even question without appearing antediluvian. Management supports the new regime of audit because it provides a tool not only for measuring productivity but also for 'incentivising' and controlling the academic workforce ('discipline and publish' is how some academics have characterised this new regime of 'constant visibility' before the gaze of anonymous officials). The result is that university departments and even individual staff members must now be 'benchmarked' against each other and then ranked in competitive national and international league tables-the results immediately pasted onto the Internet so that 'transparency' and 'quality' are assured. ${ }^{1}$

Reflecting on this, Michael Power aptly comments that 'we seem to have lost our ability to question or be publicly skeptical about the fashion for quality assurance: they appear as "natural" solutions to the problems we face' (Power 1994: 41). Could it be that these 'solutions' are in fact part of the problem? What is needed, perhaps is more sophisticated understanding of the concept of 'accountability', one that distinguishes between its democratic and autocratic forms.

Within the university sector in Britain, 'accountability' has increasingly become conflated with accountancy and with the methods of financial audit-from whence many of the techniques and approaches derive. As our contributors show, that model of financial audit appears to have mutated and spread not only across professions, but also across continents, from the UK and North America to Brazil, Australasia and continental Europe. The common assumption is that the methods used by international auditing firms provide a model of 'best practice' and accountability that is transferable anywhere in the public sector. The paradox here is that the financial world is littered with examples of accountancy fraud and regulatory failure involving these companies and their methods (Enron, WorldCom and the Bank of Credit and Commerce International being only the most spectacular). As Michael Power observes, audits have a remarkable capacity to be invulnerable to their own failure (Power 1994: 7). Moreover, most of the leading global auditing firms are highly secretive and rarely provide any research access to client data or allow researchers to study their organisational life. We tend to assume that because their business is making organisations more 'accountable' and 'transparent', they work to promote the public interest. However, as Prem Sikka, Professor of Accounting, Finance and Management at Essex University, points out, 'the internal governance of accountancy firms is more disposed towards profit maximisation, possibly at the expense of wider social obligations' (Sikka 2003: 5). Indeed, most of the complex offshore structures used by Enron to conceal its debts and transactions were allegedly devised by KPMG (Sikka, pers. comm.).

Accountancy models of accountability are in many cases introducing new relations of power between the university's workforce and management. Academics are becoming ever more 'accountable' yet increasingly more insecure as tenure is restricted to the privileged few, and as flexible, part-time and fixed-term teaching contracts become the norm. Both Susan 
DiGiacomo and Mary Huber's articles in this issue highlight the striking correlation between the rise of accountability and the increasing casualisation of the workforce. As DiGiacomo illustrates, what we have witnessed is the 'normalisation' of a flexible reserve army of academic labour, yet our professional associations, despite their vocal concern with professional ethics, are curiously silent in their response to this ethically compromising situation. Estimates for the UK suggest that the university sector may have become even more casualised than the catering industry (NATFHE 2002). While some university staff-and particularly the staff unions-complain that this undermines academic freedom and inhibits recruitment into the profession, from a managerialist perspective, casualisation (or 'flexibilisation' as it is often termed) is often perceived as functional and desirable. As one university Vice Chancellor in the UK candidly admitted, a measure of insecurity among academics is 'perhaps not a bad thing' as it 'incentivises staff' and encourages them to enhance their performance. ${ }^{2}$ Huber raises the question of whether this new regime is discouraging academically strong people from entering and/or remaining in the academic profession. This seems undoubtedly to be the case. For example, between 1996 and 2000, on the back of a successful score in the competitive 'Research Assessment Exercise', the Anthropology Department at Goldsmiths College significantly made four new junior lectureship appointments. These were permanent jobs. The field of candidates was unexpectedly large (over one hundred applicants for each post), so it would be fair to say that the department was able to select from among the very best of the new generation of young anthropologists, with three successful candidates being women. By 2002 all three women had left: one to take up a job-share, another to develop a career as a writer (and to spend more time with her child) and the third to take up a career as a masseuse. One of these women summed up her experience of academic work: 'I don't know how people here manage to do it. I want a life' ${ }^{3}$

That statement arguably reflects and embodies a wider concern within academia and other professions about the widely perceived loss of the autonomy and freedom that were hitherto regarded as two of the defining qualities of an academic career. Part of the definition of a 'professional' is someone who sets-and lives by-their own standards of quality. Since the 1980s-as the case studies in this collection show-that function has increasingly been removed from faculties, and relocated in external bodies of one kind or another, whose agendas and concerns are very different from the kinds of values and standards traditionally associated with higher education. What is often overlooked in this rather depressing scenario is the collusion of academics themselves in these processes of coercive accountability. Indeed, the whole system of audit relies, in large measure, on the active compliance of academics; on their willingness to collude in the policing of their colleagues and themselves. As Jolly (this issue) observes, that 'normative compliance' may cease to operate in situations where the policing aspects of audit become too heavy handed. Huber (this issue) makes an important argument for becoming more intellectually serious about understanding the way pedagogy and public scholarship are being shaped by wider economic and political processes. As she says, if faculties don't take charge of their own affairs, someone else will. Taking charge of one's own affairs is perhaps simply a restatement of what it means to be a professional. The first step in this process must surely be to be more conscious and critical of 
what is happening to our profession. The second step is then to reclaim the language through which we are being held to account. Not everything that is countable 'counts', as Einstein says. Perhaps the key task is to create our own yardsticks for quality and excellence so that the things that do matter are made to count.

To return to our opening questions: how are universities being made more responsive to the values of the 'enterprise culture', and how are they being transformed by these new managerialist regimes of audit and accountability? These are the questions explored in the articles in this issue. We hope that our findings will stimulate wider comment and reflection both among anthropologists and academics, and among those in professions outside of academia.

Don Brenneis is Professor of Anthropology at the University of California, Santa Cruz.

Cris Shore is Professor of Social

Anthropology at the University of Auckland, New Zealand.

Susan Wright is Professor of Educational Anthropology at the Institute of Educational Anthropology, Danish University of Education.

\section{Notes}

1. See inter alia, Amit 2000; Charlton 1999; Gledhill 2001.

2. These comments were made in 2002 by the late Professor Ben Pimlott (former Warden of Goldsmiths College), at a meeting of the Association of University Teachers (AUT).

3. The point here is not so much that the increasingly stressful work conditions impact most negatively upon women (although statistics would probably bear this out), but rather their deleterious effects upon parents, particularly those with young children. The long hours and high productivity norms demanded by the audit culture typically contradicts those 'equal opportunities' and 'family-friendly' policies that many universities and organizations like to espouse.

\section{References}

Amit, Vered 2000 'The University as Panopticon', in M. Strathern (ed.) Audit Cultures: Anthropological studies in accountability, ethics and the academy, London: Routledge.

Charlton, Bruce 1999 'QAA: Why we should not collaborate' Oxford Magazine, 169: 8-10.

Collini, S. 2003 'HiEdBiz', London Review of Books 25 (21): 3-9.

Gledhill, John 2001 'Facing the future: anthropology and the transformation of the university', Anthropology in Action, 8 (1) 4955.

NATFHE (National Association of Teachers of Further and Higher Education) 2002, Memorandum submitted to the House of Commons Select Committee on Science and Technology (24 June 2002), APPENDIX 27, London: House of Commons http:/ / www. parliament.the-stationeryoffice.co.uk/pa/cm200102/cmselect/ cmsctech/1046/1046ap30.htm, accessed 20 November 2004.

Power, M. 1994 The Audit Explosion, London: Demos.

Readings, B. 1996 The University in Ruins, Cambridge Mass.: Harvard University Press.

Shore, C. and Wright, S. 1999 'Audit Culture and Anthropology: neoliberalism in British Higher Education', Journal of the Royal Anthropological Institute 5 (4): 557-575.

- 2004 'Whose Accountability? Governmentality and the auditing of universities', Parallax 10 (2): 100-116.

Sikka, P. 2003 'Some Questions about the Governance of Auditing Firms', paper delivered to the Department of Accountancy and Management, University of Auckland, New Zealand (October). 
Smith, A. and Webster, F. 1997 The

Postmodern University? Contested Visions

of Higher Education in Society,

Buckingham: Society for Research in

Higher Education and Open University

Press.

Strathern, M. 2000 (ed.) Audit Cultures.

Anthropological Studies in Accountability,

Ethics and the Academy, London:

Routledge.

—- 2003 'Accountability Across

Disciplines', paper presented to CBA

workshop, Languages of

Accountability, Cambridge University (May).

Tickel, A. and Peck, J. 2003 `Making

Global Rules. Globalisation or

Neoliberalization?' in A. Tickel and J.

Peck (eds) Remaking the Global Economy.

Economic-Geographical Perspectives,

London: Sage.

University of Auckland. 2003 Draft

Interim Profile for 2004, 2005 and 2006,

Auckland: University of Auckland. 